\title{
A COMPARISON OF ODOUR COMPLAINT STATISTICS WITH MODEL CALCULATIONS OF ODOUR EPISODES
}

\author{
Günther Schauberger, Institute of Medical Physics and Biostatistics, University of Veterinary Medicine \\ Vienna, Veterinärplatz 1, A 1210 Vienna, Austria \\ Martin Piringer and Erwin Petz, Central Institute for Meteorology and Geodynamics, Department of \\ Environmental Meteorology, Hohe Warte 38, A 1190 Vienna, Austria
}

\begin{abstract}
The Austrian odour dispersion model (AODM) is a Gaussian model suitable for the prediction of ambient odour concentrations. Based on cumulative frequency distributions of calculated odour concentrations at receptor points, separation distances are obtained defined by odour impact criteria chosen as a combination of odour threshold and probability of threshold exceedance. At these separation distances, depending on the wind direction, the occurrence of odour sensation is analysed and compared with the well-known time pattern of the complaint statistics for odour.
\end{abstract}

Here, the AODM is used to calculate separation distances for an odour threshold of 1 odour unit (OU) per cubic metre exceeded in 3\% of the year. At a site in the Austrian North-alpine foreland, direction-dependent separation distances for a 1000 head pig unit (calculated on the basis of a two-year time series of meteorological data) lie between $99 \mathrm{~m}$ for northerly winds and $362 \mathrm{~m}$ for westerly winds. For these directiondependent separation distances we analysed when odour sensation can be expected in relation to meteorological parameters as well time of the day and year. For the main wind directions, West and East, odour sensation can be expected more often for higher wind velocities and a neutrally or stably stratified atmosphere around sunset. North and South winds show the typical diurnal variation of a local valley wind system with predominantly northerly daytime up-valley and southerly night-time down-valley winds. Odour sensation is therefore most likely around noon for North wind and during night time for South wind. This time pattern of the calculated odour sensation doesn't fit to the time pattern of the complaint statistics which shows complaints to occur predominantly in the afternoon and evening hours of the warm season when residents are outside. The presented comparison of odour complaint statistics with the calculated odour episodes is a helpful tool to find out when odour is perceived as most annoying. As a result, the evaluation of these values by the odour impact criteria should not only be based on statistical limits as it is done today but also by considering the annoying potential of odour due to the behaviour of the neighbours. Therefore the odour episode should be weighted by the time of the day and time of the year, as is done with the limit values for noise.

\section{KEYWORDS}

odour, livestock, pig, annoyance, separation distance, dispersion model, complain

\section{INTRODUCTION}

Odour is one of the major nuisances from livestock husbandry especially in the swine industry causing an increasing need for odour related research (Thu, 2002). The final report of the Iowa State University and The University of Iowa Study Group (2002) defines odour, besides hydrogen sulphide and ammonia, as emission 
source which has been of major concern by residents in the vicinity of livestock. Environmental agencies are confronted by complaints of people living in the vicinity of animal producing farms. Reports about these complaints show similar time patterns (Strauss et al. (1986); Schiffman, 1994; Lohr (1996), concentrated during the warm season and in the afternoon and evening hours.

In this paper the time pattern of the complaints is compared to the time pattern of odour sensation calculated by the Austrian Odour Dispersion Model AODM described recently (Schauberger et al. 2001 and 2002). The AODM consists of three modules: the first calculates the odour emission of the livestock building, the second estimates mean ambient concentrations using the Austrian Gaussian regulatory dispersion model, and the last transforms the mean odour concentration of the dispersion model to instantaneous values that depend on wind velocity and atmospheric stability. The direction-dependent separation distance is defined as the distance from the source where a sensation level dependent on a pre-selected odour impact criterion occurs. The odour impact criteria used in this study are a combination of odour threshold and probability of threshold exceedance (Schauberger et al., 2001).

The calculated odour concentrations have to be evaluated against the odour impact criteria. Watts and Sweeten (1995) suggest the FIDO factors, which can be used to assess odour nuisance.

In this paper we investigate if odour sensation can be expected to occur at the calculated direction-dependent separation distances. We analyse the modelled odour perception according to meteorological parameters (wind direction, wind velocity, stability of the atmosphere) as well as time of the day and year, and compare these results to the complaint statistics of odour.

\section{MATERIALS AND METHODS}

Only a brief summary is given here; details are found e. g. in Schauberger et al. (2002).

\section{Short description of the AODM}

The calculation of odour release is based on a steady-state balance of the sensible heat flux, used to calculate the indoor temperature, and the ventilation rate of the livestock unit (Schauberger et al., 2000b). The corresponding odour flow in $\mathrm{OU} / \mathrm{m}^{3}$ is assessed by a simple model for odour release described by Schauberger et al. (1999 \& 2000b). The chosen system parameters typical for a livestock building in middle Europe (Schauberger et al., 1995) can be found in detail in Schauberger et al. (2001b and 2002). The results were calculated for a mechanically ventilated pig fattening unit with 1000 pigs. The following parameters were calculated every half-hour over the two year period: outlet air temperature, outlet air velocity, volume flow of the ventilation system, odour concentration of the outlet air. The odour flow in OU/s is calculated by the product of the volume flow of the building in $\mathrm{m}^{3} / \mathrm{s}$ and odour concentration of the outlet air in OU/m 3 .

The mean ambient odour concentrations are calculated using the Austrian Gaussian regulatory dispersion model (ÖNorm M 9440, 1992/96), a Gaussian plume model for single stack emissions. The model has been validated internationally (e. g. Pechinger and Petz, 1999). The mean odour concentrations of the dispersion model are transformed to instantaneous values depending on wind velocity and atmospheric stability. The meteorological background to calculate the instantaneous values using a peak-to-mean parameterisation is described in detail by Schauberger et al. (2000a). 


\section{Calculating sensation and separation distance}

The separation distance is calculated for eight wind direction classes (sectors of $45^{\circ}$ ) in two steps: First, sensation distances, defined as distances from the source where the momentary odour concentration is $1 \mathrm{OU} \mathrm{m}^{-3}$, are calculated for each half-hourly period of the meteorological 2-year time series.. The second step is the calculation of the separation distance. Therefore, selected limits of the combination of odour concentration threshold $\mathrm{T}$ and probability of the threshold exceedance $\mathrm{p}_{\mathrm{T}}$ are taken. For the calculation presented here we selected a threshold of $1 \mathrm{OU} / \mathrm{m}^{3}$ and a probability of the threshold exceedance of $3 \%$ indicating that, during a typical year, there are 525 out of 17520 half hourly periods $(3 \%)$ during which the ambient odour concentrations will be momentarily above $1 \mathrm{OU} / \mathrm{m}^{3}$. On the basis of the cumulative probability of the sensation distances for each of the eight wind direction sectors, the separation distances are calculated for the selected odour impact criterion. For a selected wind direction sector, the distance at which this definition is fulfilled, is called separation distance. E.g. for North wind, the corresponding separation distance points to the South of the odour source (Schauberger et al., 2002).

\section{Meteorological conditions}

The meteorological data for January 30, 1992 to January 31, 1994 were collected at Wels, a site representative of the Austrian flatlands north of the Alps. The sample interval was 30 minutes. The city of Wels in Upper Austria is a regional shopping and business centre with a population of about 50,000. The surrounding area is rather flat and consists mainly of farmland. The mean wind velocity $10 \mathrm{~m}$ above the mean roof top level of $15 \mathrm{~m}$ is $2.2 \mathrm{~m} / \mathrm{s}$ with a maximum velocity of about $13 \mathrm{~m} / \mathrm{s}$. The distribution of wind directions is shown in Fig. 1a.

Discrete stability classes have been determined based on sun elevation angle, cloud cover and low cloud base height, and wind speed (Reuter, 1970). The cloud data are measured at the Linz-Hörsching airport, about $13 \mathrm{~km}$ from Wels. Within the Reuter scheme, classes 2 to 7 can occur in Austria. Stability classes 2 and 3 , which by definition occur only during daylight hours in a well-mixed boundary layer, class 3 allowing also for cases of high wind velocity and moderate cloud cover, occur in $26 \%$ of all cases. Stability class 4 , representing cloudy and/or windy conditions including precipitation or fog, occurs day and night (43\%). Class 5 occurs with higher wind velocity during nights with low cloud cover, a situation which is not observed frequently at Wels (6\%). Classes 6 and 7 are relevant for clear nights, when a surface inversion, caused by radiative cooling, traps pollutants near the ground. Such situations occur in $25 \%$ of all cases.

\section{RESULTS}

First of all the separation distances for the 8 wind direction sectors were calculated (Tab. 1). In Fig. 1 (upper left corner), the separation distances can be compared with the distribution of the wind direction, centred at Wels. For northerly winds (for a southward separation distance), the separation distance is lowest, caused by low average wind speeds and predominantly unstable conditions associated with this wind direction sector (see Figs. 4 and 5). The highest of the direction-dependent separation distances are found for the prevailing wind directions West and East with $362 \mathrm{~m}$ and $348 \mathrm{~m}$, respectively.

At these distances, odour sensation occurs with a probability of 3\% which is the exceedance probability of the selected odour impact criterion. These 3\% of odour occurrence were analysed according to time of the day, time of the year, wind velocity and the stability of the atmosphere. 
For each of these four parameters, expected odour episodes were compared to those observed for the four cardinal wind direction classes. Odour episodes are called "expected" if they are evenly distributed over all meteorological situations. An odour episode calculated at the separation distance is named "observed". At this distance an odour episode is defined if one or more consecutive odour concentration values are above the odour sensation threshold of $1 \mathrm{OU} / \mathrm{m}^{3}$. In Figs. 2 to 5 we compared the frequencies of the observed and the expected odour episodes and calculated the ratio of the two frequencies.

Table 1 - Relative frequency of the eight classes (class width $45^{\circ}$ ) of wind directions and directiondependent separation distances on the basis of an odour threshold of $1 \mathrm{OU} / \mathrm{m}^{3}$ and a probability of threshold exceedance of $3 \%$. The maximum and the minimum distances are marked in bold.

\begin{tabular}{|c|c|c|c|}
\hline $\begin{array}{c}\text { Wind } \\
\text { direction } \mathrm{i}\end{array}$ & $\begin{array}{c}\text { Relative } \\
\text { frequency } \\
\left(\mathrm{p}_{\mathrm{i}}\right), \%\end{array}$ & $\begin{array}{c}\text { Direction for the } \\
\text { separation } \\
\text { distance }\end{array}$ & $\begin{array}{c}\text { Direction dependent } \\
\text { separation distance }\left(\mathrm{S}_{\mathrm{i}}\right), \\
\mathrm{m}\end{array}$ \\
\hline $\mathbf{N}$ & $\mathbf{2 . 6}$ & $\mathbf{S}$ & $\mathbf{9 9 . 4}$ \\
\hline $\mathrm{NE}$ & 6.8 & $\mathrm{SW}$ & 218.9 \\
\hline $\mathrm{E}$ & 25.9 & $\mathrm{~W}$ & 347.7 \\
\hline $\mathrm{SE}$ & 3.4 & $\mathrm{NW}$ & 152.5 \\
\hline $\mathrm{S}$ & 5.5 & $\mathrm{~N}$ & 224.6 \\
\hline $\mathrm{SW}$ & 15.6 & $\mathrm{NE}$ & 339.9 \\
\hline $\mathbf{W}$ & $\mathbf{3 4 . 1}$ & $\mathbf{E}$ & $\mathbf{3 6 2 . 1}$ \\
\hline $\mathrm{NW}$ & 6.2 & $\mathrm{SE}$ & 208.9 \\
\hline
\end{tabular}

Figure 1 - Map of Austria with a polar diagram of the relative frequency distribution (in \%) of the wind direction (for 8 sectors with $45^{\circ}$ ), centred at Wels (site of the livestock) (Calm conditions (less than 0.7 $\mathrm{m} / \mathrm{s}$ ) as dotted line) and the separation distances (in $\mathrm{m}$ ) in the upper left corner (for 8 sectors with $45^{\circ}$ ).

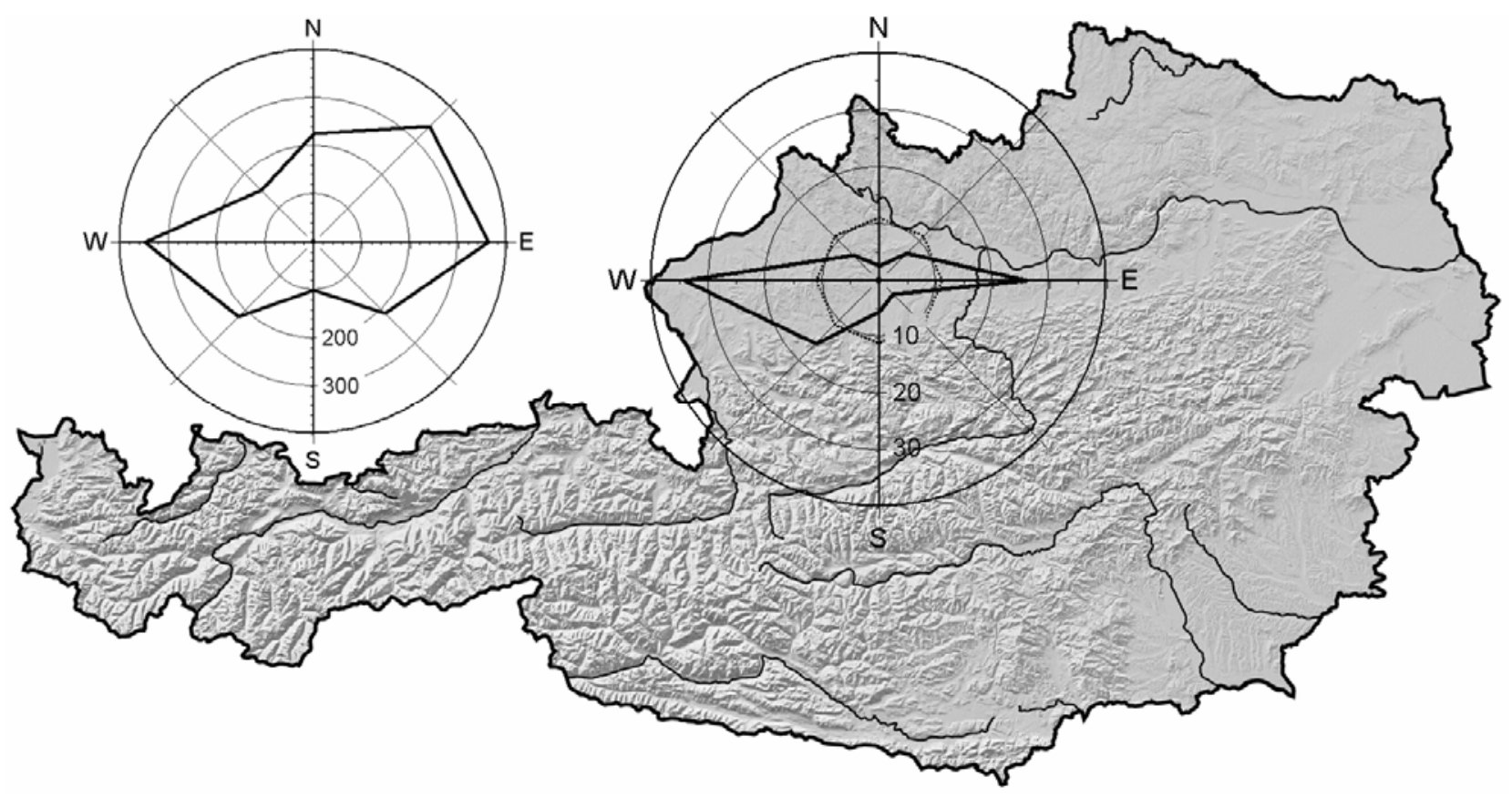


Figure 2 - Comparison of the relative frequency of expected (empty bars) and observed (filled bars) odour episodes for the time of the day. Proportion of observed to expected events (dotted line). (a) North wind, (b) East wind, (c) South wind, and (d) West wind (all $45^{\circ}$ sectors)
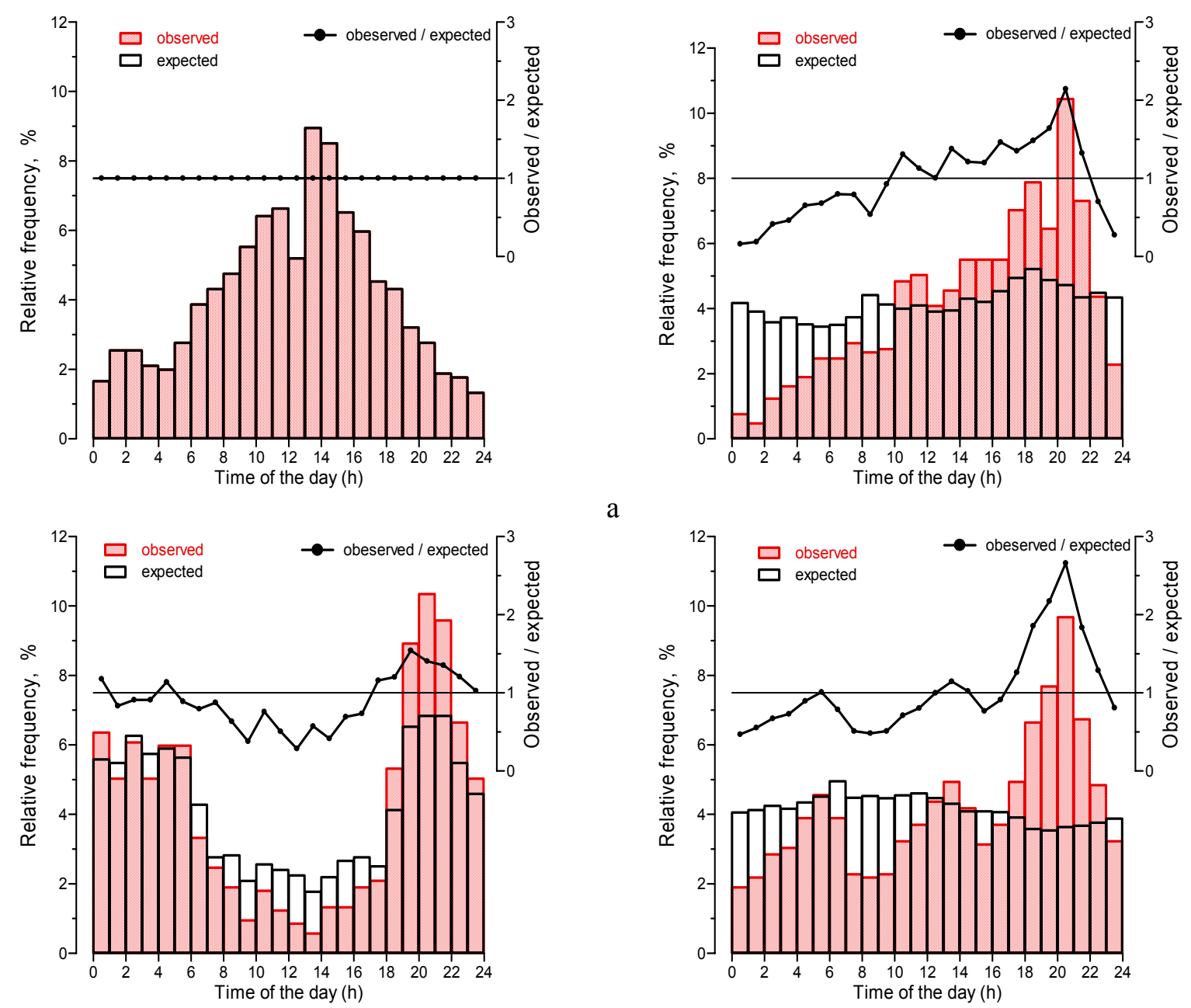

a

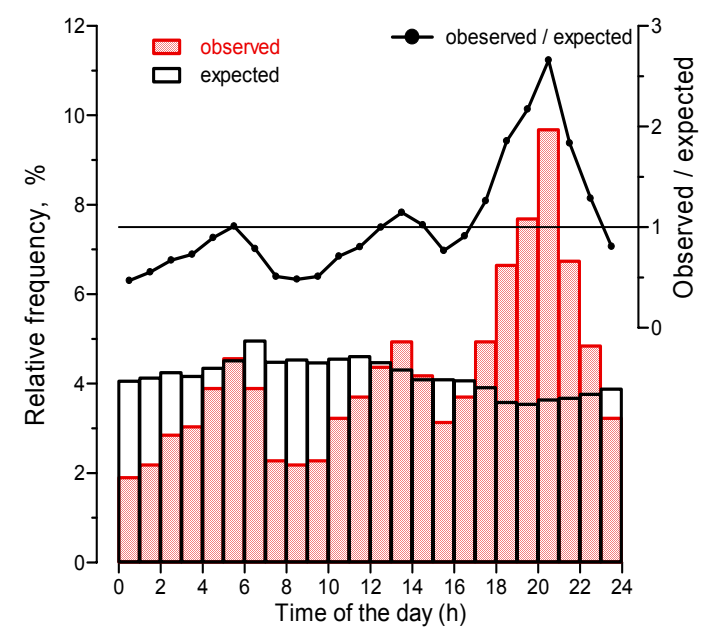

b

d

For North wind no comparison between observed and expected odour episodes is possible: The probability for North wind $(2.6 \%)$ is less than the probability of the threshold exceedance of $3 \%$ of the selected odour impact criterion. This means that all the time with North winds, odour episodes occur, and the relative frequencies of the expected and the observed odour episodes are the same.

Northerly and southerly winds show a behaviour which suggests an influence of the North-South oriented Alm river valley running into the Alpine foreland south of Wels. Northerly up-valley winds are more frequent during daytime (Fig. 2a), southerly down-valley winds more frequent during night (Fig. 2c). Therefore northerly winds are frequently associated with stability classes 2 to 4 (Fig. 5a), southerly winds with classes 4 to 7 (Fig. 5c). For both wind directions, the average wind velocity is rather small, with the $75 \%$-percentile at $1.1 \mathrm{~m} / \mathrm{s}$ for North (Fig. 4a) and at $1.9 \mathrm{~m} / \mathrm{s}$ for South wind (Fig. 4c), respectively. In accordance with these findings, odour episodes at the separation distance for northerly winds (all half-hours) show a maximum during daytime (between 7:00 and 20:00) (Fig. 2a) and occur frequently more often during the spring and summer months (Fig. 3a). For southerly winds (Fig. 2c), odour episodes at the separation distance have their maximum of occurrence in the evening (after 18:00), are frequent throughout the night, and show a local maximum in the morning (before 6:00). South wind is most frequent from late summer through autumn to January (Fig. 3c). 
Figure 3 - Comparison of the relative frequency of expected (empty bars) and observed (filled bars) odour episodes for the time of the year. Proportion of observed to expected events (dotted line). (a) North wind, (b) East wind, (c) South wind, and (d) West wind (all $45^{\circ}$ sectors)
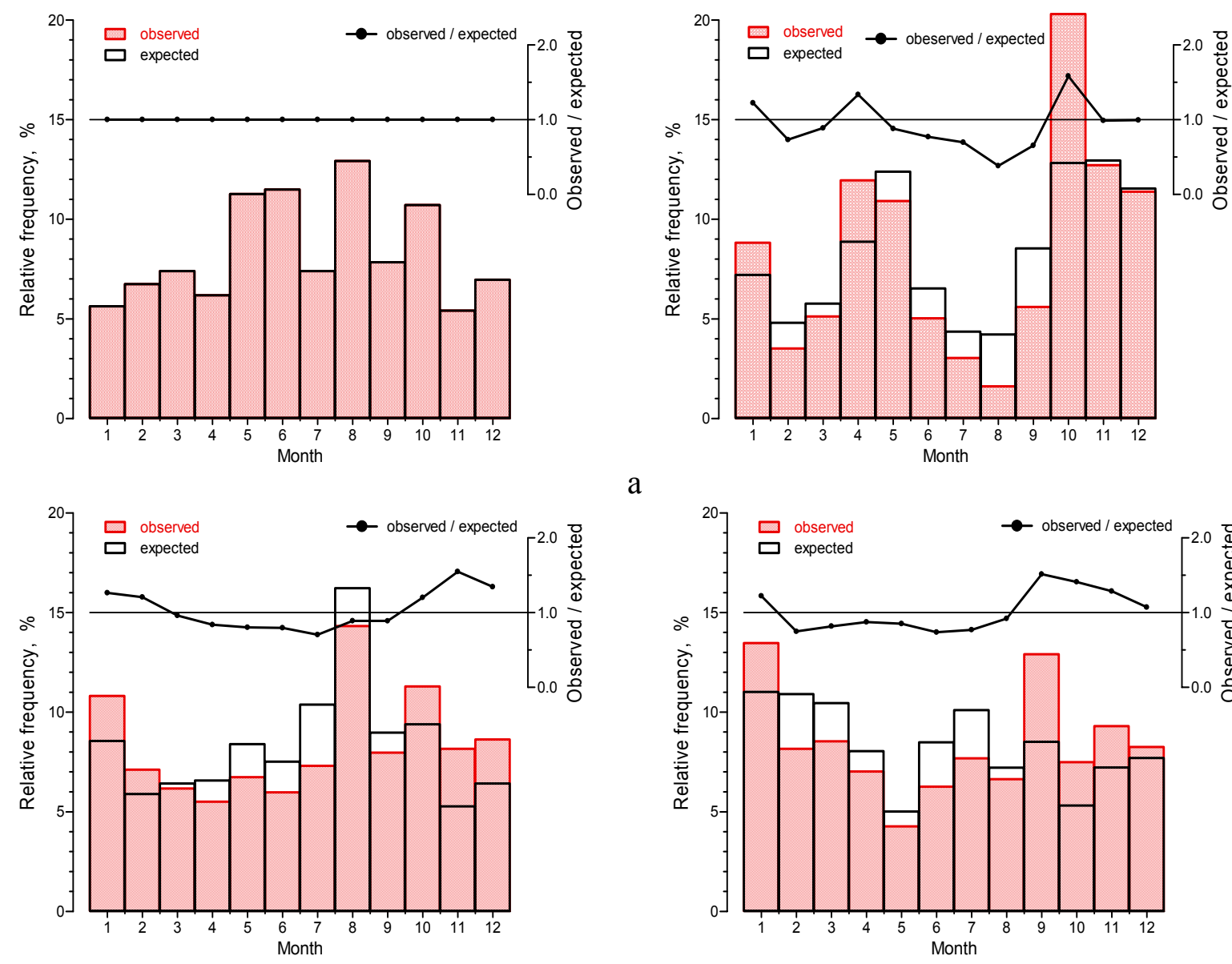

a

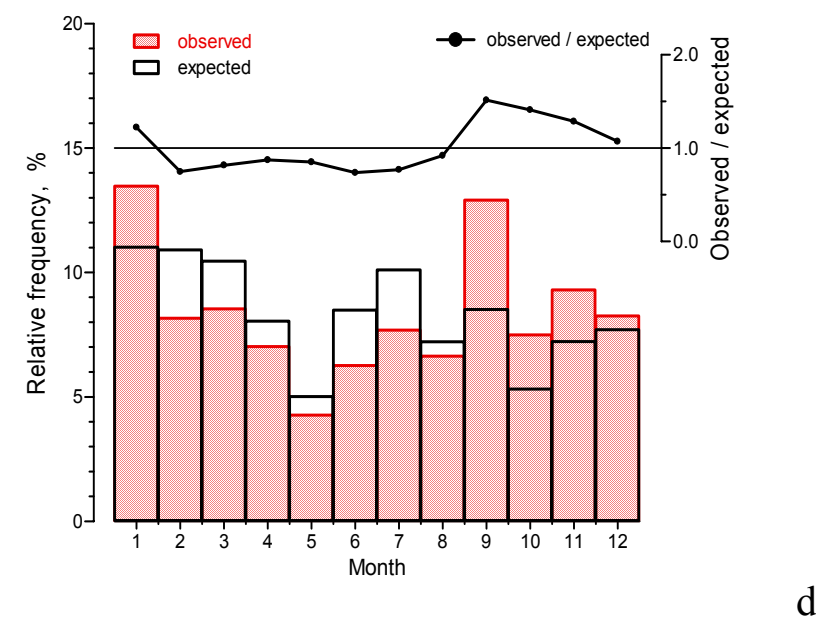

East and West winds are the dominant directions at Wels. Both directions show no strong variation over the day (Fig. 2b, 2d) and some but no systematic variability across the year (Fig. 3b, 3d). Both directions are associated with much stronger wind velocities than North and South wind (Fig. 4b, 4d): the most frequent velocities for East wind are around $3 \mathrm{~m} / \mathrm{s}$, for West wind around $4 \mathrm{~m} / \mathrm{s}$. Maximum velocities are around $9 \mathrm{~m} / \mathrm{s}$ for East wind and around $13 \mathrm{~m} / \mathrm{s}$ for West wind. The distribution of stability classes with East and West winds is relatively similar to the overall distribution (Section 2.3), due to the large frequency of these directions. Stability class 4 dominates, especially for West wind (Fig. 5d) frequently in conjunction with high wind velocities, cloudiness, and rain. Classes 2 and 3 as well as 6 and 7 are more common with East wind associated with anticyclonic conditions (Fig. 5b). For East and West winds, odour episodes at the separation distance take place more often in the second half of the day, with peaks around 22 CET (Fig. 2b and 2d), and from October to January (Figs 3b and 3d). For both directions, the dependence of odour episodes on wind velocity shows several peaks, mostly at 1 and from 3 to $5 \mathrm{~m} / \mathrm{s}$ (Fig. 4b, 4d). For East wind, odour episodes occur only with stability classes 4 to 7 (Fig. 5b); for West wind, they occur with classes 4 to 6; classes 2 and 3 are free from odour episodes for the selected odour impact criterion, which is an effect of the large separation distance for these directions (Tab. 1 and Fig. 1). 
Figure 4 - Comparison of the relative frequency of expected (empty bars) and observed (filled bars) odour episodes for wind velocity. Proportion of observed to expected events (dotted line). (a) North wind, (b) East wind, (c) South wind, and (d) West wind (all $45^{\circ}$ sectors)
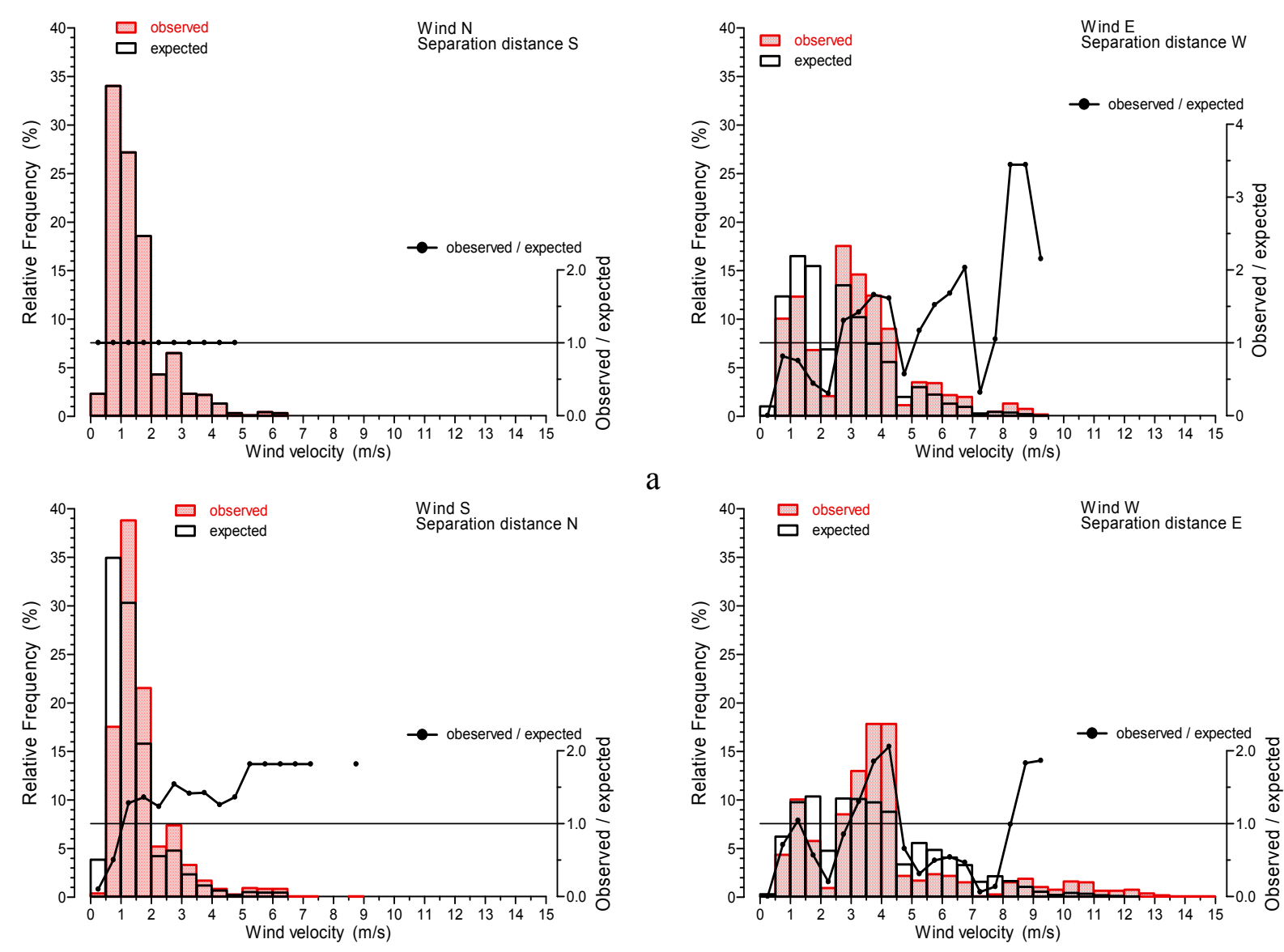

a

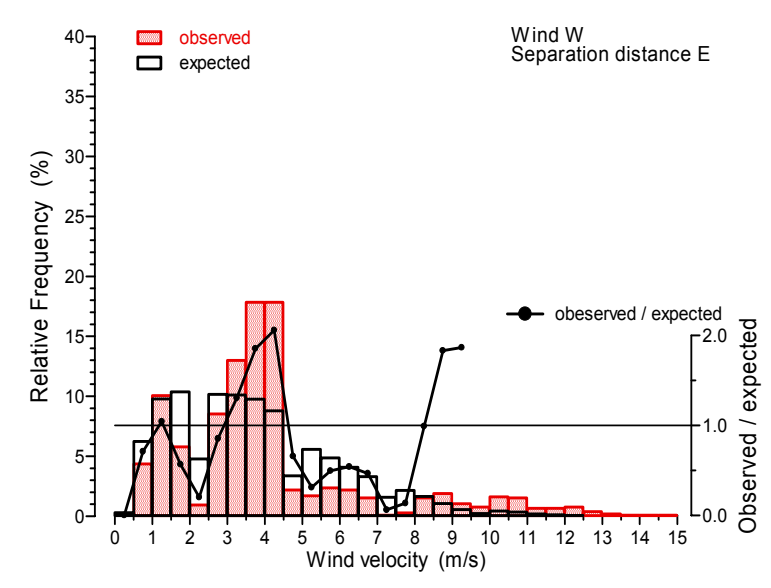

The daily frequency distribution of observed odour episodes shows a distinct maximum for all direction sectors (Fig. 2): For northerly winds, a maximum occurs in the afternoon, for the three other direction sectors in the evening hours which is also expressed by a maximum of the ratio between the frequency of the observed and expected episodes. For the annual variation (Fig. 3) no such clear time pattern could be found; however, apart from North wind, there is a tendency of more observed than expected episodes in the winter months.

An important parameter describing the nuisance potential of odour is the duration of consecutive odour episodes (Fig. 6). The duration of odour episodes was investigated in relation to the hour of the day and the day of the year. It is expressed by the size of the circles in the graph. The lines, marking the time of sunset and sunrise, separate daytime from night-time, which changes the character of the dispersion process in the atmosphere, expressed by the stability class (Section 2.3). For all four wind directions, a distinct pattern can be seen. The two wind directions ( $\mathrm{N}$ and $\mathrm{S}$ ) influenced by the valley wind system show a distinct diurnal pattern: For North wind, episodes occur at daytime (Fig. 6a), for South wind, at night-time (Fig. 6c). The occurrence of long lasting odour episodes is much smaller than for the prevailing wind directions (West and East). For the prevailing wind directions, the influence of solar radiation on the occurrence of odour episodes is less pronounced but still present (Fig. 6b, 6d). For these directions, the occurrence of odour episodes shows a minimum at midday in summer. 
Figure 5 - Comparison of the relative frequency of expected (empty bars) and observed (filled bars) odour episodes for stability of the atmosphere. Proportion of observed to expected events (dotted line). (a) North wind, (b) East wind, (c) South wind, and (d) West wind (all $45^{\circ}$ sectors)
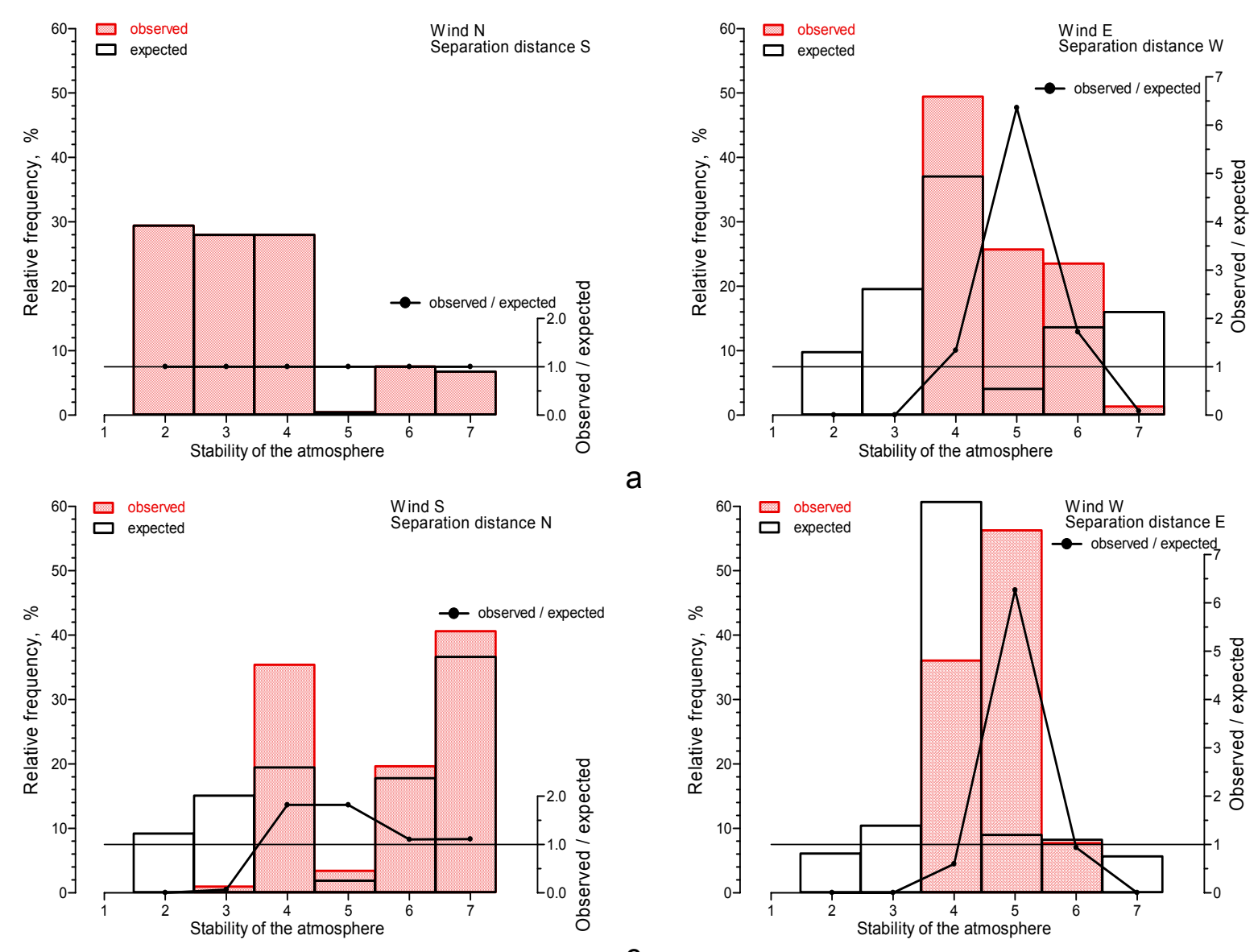

a

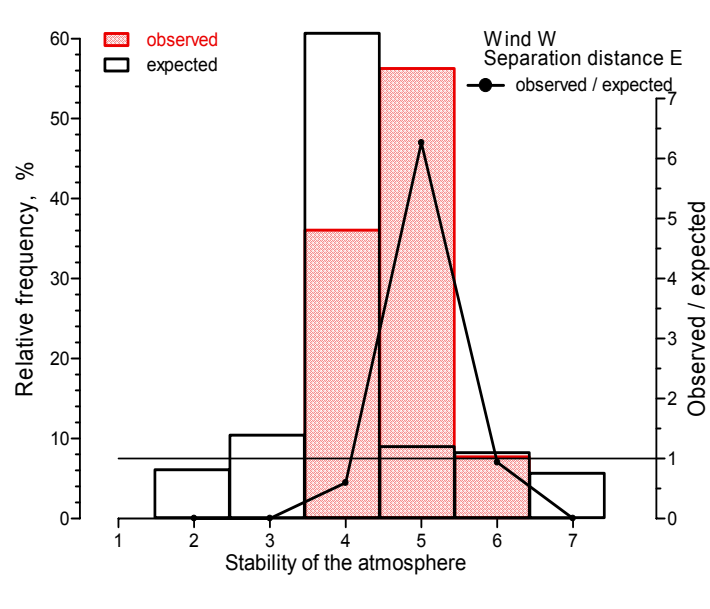

$\mathrm{b}$

$d$

\section{DISCUSSION}

In this paper, the Austrian odour dispersion model (AODM), a Gaussian model suitable for the prediction of ambient odour concentrations (section 2), is used to calculate direction-dependent separation distances, defined by odour impact criteria chosen as a combination of odour threshold and probability of threshold exceedance. At these direction depending separation distances the occurrence of odour sensation is analysed for a two year period (section 3) and compared with the well-known time pattern of the complaint statistics for odour.

Most complaints ('time of most complaint') from swine odour are recorded early in the morning or late at night under stable conditions (Schiffman, 1994). Another time of above-average complaints could well be the transition from day- to night-time, when a stable stratification evolves in the near-surface boundary layer. The results obtained applying the AODM to meteorological conditions typical for Austrian areas North of the Alps (Section 2.3) and presented in Figs 2 show, however, maximum odour probability at different times of the day: afternoon hours for northerly winds (Fig. 2a), late evening hours for easterly winds (Fig. 2b), night-time including evening and morning transition for southerly winds (Fig. 2c), and again late evening hours for westerly winds (Fig. 2d). Thus, AODM results and observations co-incide to a large extent, but also partly differ. The co-incidence is strongest for late evening hours, an indication that the AODM seems to be capable of correctly taking into account the spread of odour over longer distances in stable conditions. It should be 
emphasised here that the model is designed to predict odour perception at receptor points (e. g. neighbours), but not the occurrence of complaints at the neighbours. Moreover, the "comparison" is not direct, as the model calculations are not undertaken for a case of complaints. The assessment of odour perception by the AODM does not always coincide with the real time of nuisance complaints because the behavioural response of the neighbours to the odours cannot be included in the model.

Figure 6 - Duration of odour episodes as a function of the day of the year and the time of the day. The diameter of the circles is proportional to the duration of odour episodes. (a) North wind, (b) East wind, (c) South wind, and (d) West wind (all $45^{\circ}$ sectors). The lines mark sunrise and sunset for Wels (geographic latitude: $47.17^{\circ} \mathrm{N}$ )
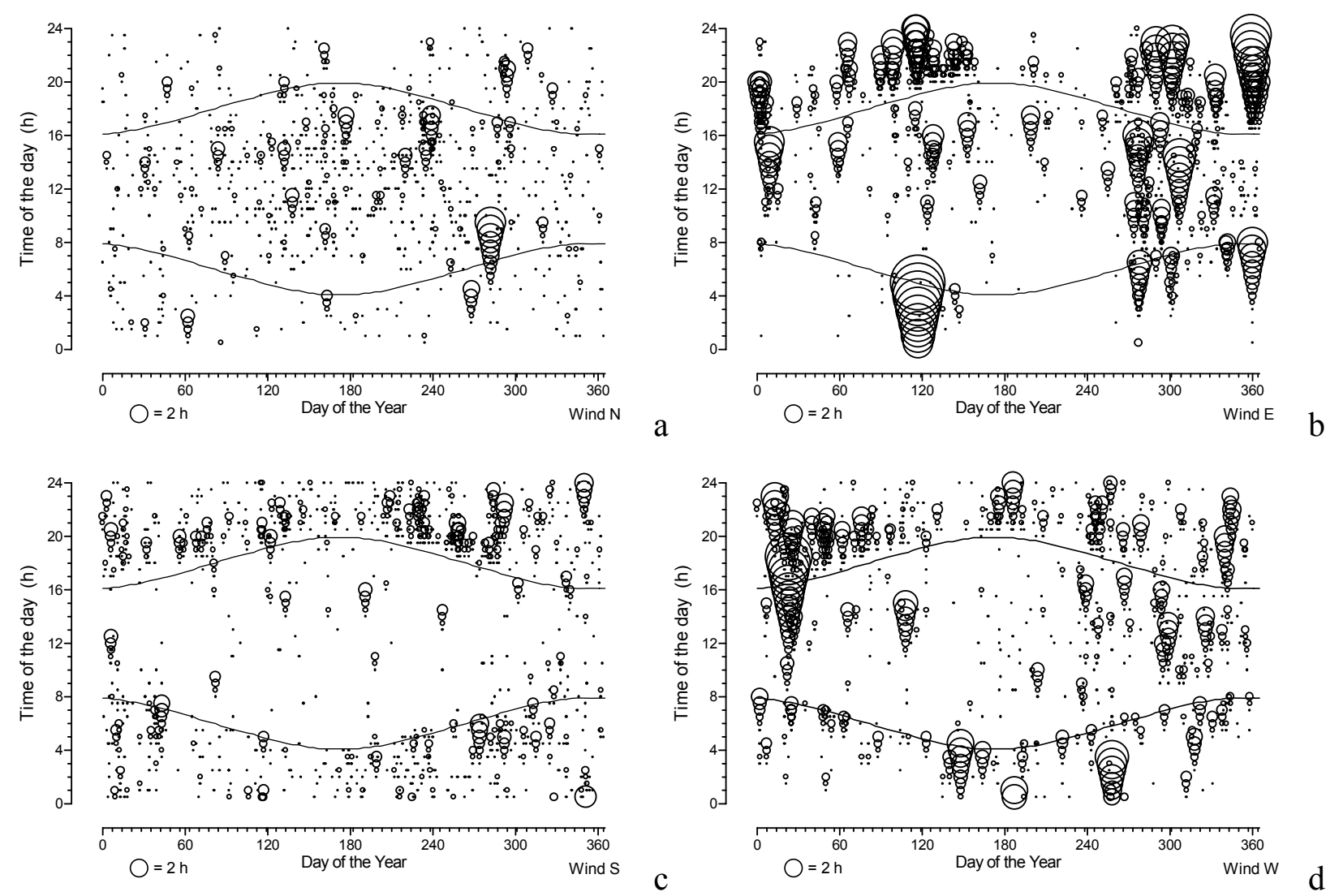

In the Canadian community Capilano (http://freenet.edmonton.ab.ca/capilano/), the following distribution of odour sensation over time was reported for 2002: $54 \%$ of odour complaints were registered between 20:00 to 23:00 and 78\% of all complaints were registered during evening hours between 16:00 - 24:00. 13\% of complaints only were registered during mid-day hours (08:00 -16:00) and 9\% during early morning hours (00:00-08:00). 67\% of all complaints were registered during June and July.

Strauss et al. (1986), in a survey about the complaints due to livestock units in Austria, found a higher probability during summer (50\%) compared to spring (34\%), autumn (25\%), and winter (1\%). Only $26 \%$ of the persons interviewed feel constantly annoyed all year. Lohr (1996) investigated the odour perception for the four seasons by the frequency of odour exposure (number of odour sensation noticed per month) and found 3.24 for summer, 1.18 for spring, 0.71 for autumn, and 0.12 for winter. The duration of exposure (hours per odour sensation) shows a similar pattern: 16.59 for summer, 12.00 for spring, 10.59 for autumn, and 2.47 for winter. The AODM calculation of the direction-dependent separation distances for Wels does not show such a clear dependence of odour sensation on the season (Fig. 3). The results, however, indicate high odour levels during summer for North wind and South wind in August only, whereas for East and West winds, summer months show a minimum in odour sensation. The AODM predicts instead more frequent odour perception for 
the winter months. A residents based field observation of odour in the vicinity $\left(4.8 \times 4.8 \mathrm{~km}^{2}\right)$ of livestock buildings was done by Jacobson et al. (2001). Odour was detected in $71 \%$ during neutral to slightly stable conditions and during light winds $(<2.5 \mathrm{~m} / \mathrm{s})$. Odour sensation occurred predominantly during the warm season and either in the early morning or during evening hours. Jacobson et al. (2001) found the following reasons: increased odour emission due to higher temperatures and more outdoor activities of residents during summertime.

One reason why odour complaints are registered more often in the warm season compared to the presented model calculations could be a temperature sensitivity of odour perception (Strauss et al., 1986). The sensitivity of the neighbours increase with increasing outdoor temperature; this effect is not included in the AODM calculations. Fang et al. (1998) found a weak linear correlation between the acceptability of air quality and the enthalpy of the air with the restriction that the investigation was done for indoor air and a limited range of both air temperature $\left(18-28^{\circ} \mathrm{C}\right)$ and relative humidity $(30-70 \%)$. The discrepancy can also be explained by the variation of the odour annoying potential caused by the synchronised behaviour of neighbours (e.g. time to stay outdoors, open windows) which is also not reflected in the usual odour impact criteria.

A second reason for the discrepancy between complaint statistics and model calculations results from not including the time pattern of the behaviour of the neighbours in the odour impact criteria. It has to be discussed if the odour impact criteria, defined solely by a probability of exceedance of the selected odour threshold, are sufficient to guarantee protection with respect to the time of the day or the season of the year. It is obviously not the same with respect to odour reception if odour sensation of the same concentration occurs e.g. around sunset in summertime or during night-time in winter. The situation is complicated because odour sensation is not equally distributed over the time of the day and the months of the year (diurnal variation: Figs 2; annual variation Figs 3). In addition to the odour impact criteria, the local meteorological situation has a strong impact on possible odour nuisance from livestock farming.

The comparison of odour complaint statistics with the meteorological situation could be helpful to find out when odour is perceived as most annoying. This could help to weight the odour sensation episodes, calculated by a model like the one presented to get a better fit of the model calculations to the observed complaints.

Odour is an airborne emission which can be handled by well-known dispersion models. The difference between odour and other airborne substances is the non-linear dose response relationship of odour. The perceived odour intensity of the human nose is not proportional to the odour concentration. Odour sensation can only be observed if the odorant concentration is higher than the odour threshold of the substances. Due to fluctuations an odour sensation can take place even if the mean odorant concentration is lower than the odour threshold. This means that a mean value can not be used to assess the human odour sensation.

To use dispersion models for odour emission two different approaches are under discussion. The first is the use of a conventional dispersion model, which delivers mean values for an integration period of 30 to 60 minutes. Most of these models are used for regulatory purposes. The disadvantage of such models is the underestimation of the odour concentration at a receptor point, depending on the stability of the atmosphere and the travel time (distance) of the emission. This underestimation has to be compensated by the applied odour impact criteria which define the proportion of time which can be exceeded by a certain odour concentration. The second approach is the assessment of the odour concentration over the duration of one single breath (about 4 to $5 \mathrm{~s}$ ) by using a so-called peak-to-mean ratio. Such an assessment of the maximum expected odour concentration mimics the odour sensation of a human nose in a more realistic way. In this paper we used the Austrian Odour Dispersion Model (Schauberger et al., 2000 and 2002a) which is based on the regulatory Gaussian dispersion model and a module which takes into account turbulent mixing, to calculate the peak-to-mean ratio. The peak-to-mean ratio is reduced with increasing distance from the source using the wind velocity and the stability of the atmosphere. In Germany a constant peak-to-mean ratio of 10 is used, leading to an overestimation of the momentary odour concentration especially for larger distances.

Copyright ${ }^{\mathcal{O}} 2006$ Water Environment Federation. All Rights Reserved 
The definitions of the various national odour impact criteria differ to quite an extent. Miedema and Ham (1988) and Miedema et al. (2000) found a strong relationship between the 98 percentile of the odour concentration and the percentage of the highly annoyed neighbours. They used an ambient odour concentration for an integration time of 1 hour, calculated by a dispersion model without consideration of the peak-to mean ratio. In Germany, the odour impact criterion is defined by an exceedance probability of $10 \%$ for a threshold of $1 \mathrm{OU} / \mathrm{m}^{3}$. To apply this odour impact criterion, the calculated odour concentration (one hour mean value of the regulatory dispersion model) is multiplied by a constant factor of 10 .

This demonstrates that the representative time scale for the ambient odour concentration (between 60 minutes and some seconds), calculated by the dispersion model and the odour impact criteria are not independent. An underestimation of the perceived odour concentration by neglecting the peak to mean ratio is compensated by a strong criterion (Miedema et al, 2000), whereas an overestimation of the perceived odour concentration e. g. by a constant factor 10 (Germany) is compensated by weaker criteria. The source type (area or point; height), the distance between source and receptor, and the stability of the atmosphere are the main variables of the peak to mean ratio (Schauberger et al., 2000a and 2002), causing its decrease with distance, static stability, and wind speed. The Environment Agency, UK (2002), however, suggests to just use the 1 hour mean value as in Miedema et al. (2000), without correction by a peak to mean factor.

Apart from the exceedance probability, the odour concentration threshold of the impact criterion is of importance. The odour is measured by the human nose as a sensor by comparing a diluted odour sample with odour free air. This means that the detection threshold of $1 \mathrm{OU} / \mathrm{m}^{3}$ can only be perceived in an odour free environment (laboratory). Therefore the perceived odour concentration in the field must be higher than $1 \mathrm{OU} / \mathrm{m}^{3}$ to be distinguished against the background concentration. Field experiments must be designed such that an odour source can be distinguished against the background odour. Nicell (1994) assumes an odour concentration of $3 \mathrm{OU} / \mathrm{m}^{3}$ to allow for a discrimination, and one of $5 \mathrm{OU} / \mathrm{m} 3$ for unmistakable perception (also defined as a complaint level).

Further on, the perception of the odour intensity goes with the logarithm of the odour concentration according to the Weber-Fechner law (e. g., Misselbrook et al., 1993). Based upon laboratory-based experiments on perceived intensity, the Environment Agency, UK (2002), defines: $1 \mathrm{OU} / \mathrm{m}^{3}$ is the point of detection, $5 \mathrm{OU} / \mathrm{m}^{3}$ is a faint odour, and $10 \mathrm{OU} / \mathrm{m}^{3}$ is a distinct odour. The discrepancy between the definition of $1 \mathrm{OU} / \mathrm{m}^{3}$ in the laboratory by using odour free air and the situation in the field was solved by introducing the sniffing unit (van Langenhove and van Broeck, 2001; Defoer and van Langenhove, 2003).

All these aspects of the odour impact criteria show the difficulties to compare various methods used in different countries.

In this paper the separation distance was defined by an impact criterion of $1 \mathrm{OU} / \mathrm{m}^{3}$ and an exceedance probability of 3\%. The calculated separation distance depends strongly on the wind statistics and the stability of the atmosphere (Fig. 1 and Tab.1). For the four cardinal directions the occurrence of odour sensation was calculated at the specific separation distance.

Then the occurrence of the odour sensation was analysed according to the FIDO (frequency, intensity, duration and offensiveness) factors which were suggested by Watts and Sweeten (1995) to assess odour nuisance. In New Zealand (Ministry for the Environment, 2003) and Victoria, Australia (Department of Sustainability and Environment, 2000), a fifth factor, the location, in addition is in use. This factor describes the nuisance with regard to the sensitivity of the receiving environment. The location factor can directly be compared with the factor reasonableness, suggested by Miner (1995). He defines reasonableness of odour sensation as odour causing fewer objections within a community where odour is traditionally part of the environment. For example, it is expected that rural smells will occur as part of the rural environment and industrial smells in industrial areas. Problems then often arise if incompatible activities are located near each other. For example, 
complaints about existing intensive farming operations often occur when land use in the vicinity is changing. Lohr (1996) found that personal knowledge of the operator of the livestock unit, long term residency, economic dependence on farming, familiarity with livestock farming and awareness of the agriculturalresidential context are related to a reduced incidence of formal complaints. An assessment of this factor is often done by the land use category where the neighbours are situated. A pure residential area has a higher protection level than a rural area.

In many national guide lines, the separation distance between residential houses and livestock buildings is modified according to the reasonableness and/or location factor (e.g., Austria (Schauberger et al., 1997; Schauberger and Piringer, 1997a and 1997b), The Netherlands (Ministrie van Landbouw, 1991), Germany (VDI 3471, 1986; VDI 3472, 1986), and Switzerland (Richner and Schmidlin, 1995)). For pure residential areas the protection level is higher compared to rural sites. E.g., the separation distance for rural sites, calculated by the Austrian guideline, is half of the distance compared to pure residential areas. In New South Wales, Australia (NSW Environmental Protection Authority, 2001), the odour threshold CT depends on the population density $\mathrm{D}$ (inhabitants $\left./ \mathrm{km}^{2}\right)$ by $\mathrm{CT}=-(\log \mathrm{D}-4.5) / 0.6\left(\mathrm{eg}, 2 \mathrm{OU} / \mathrm{m}^{3}\right.$ for urban areas (D is about $2000 / \mathrm{km}^{2}$ ) and $4 \mathrm{OU} / \mathrm{m}^{3}$ for rural sites (D is about $\left.125 / \mathrm{km}^{2}\right)$ ).

In a similar way this objective is included in the odour impact criteria for the evaluation of dispersion models. An adaptation of the protection level is realised by one of the two parameters of the impact criteria. In Germany the exceedance probability is growing to reduce the protection level, in Australia the adaptation of the impact criteria is done by the odour threshold. An overview of the odour impact criteria and the corresponding land use categories used in several countries, can be found in Schauberger et al. (2001).

\section{CONCLUSIONS}

The Austrian odour dispersion model AODM is used to predict the occurrence of odour perception. The evaluation of the direction-dependent separation distances according to the daily (Fig.2) and yearly course (Fig. 3) as well as for wind speed (Fig. 4) and atmospheric stability (Fig. 5) leads to a calculated occurrence of odour sensation which differs from various odour complaint statistics which show odour to occur predominantly during the evening hours of warm summer days. Reasons for this discrepancy lie in the temperature sensitivity of odour perception and in the behaviour of neighbours which cannot be taken into account by the AODM. As a result, the evaluation of these values by the odour impact criteria should not only be based on statistical limits as it is done today but also by considering the annoying potential of odour due to the behaviour of the neighbours. Therefore the odour sensation should be weighted by the time of the day and time of the year, as is done with the limit values for noise. This means that besides the suggested frequency, intensity, duration, and offensiveness (FIDO) factors, a diurnal and annual weighting should be introduced in the odour impact criteria which reflects the outdoor behaviour pattern of neighbours.

The results of this study lead to the following open questions

- Is an odour impact criterion, defined by a threshold and an exceedance probability, an appropriate method to assess the annoying level?

- Should we weight odour sensation by time of the day and time of the year to take into account the time pattern of the behaviour?

- Is odour perception sensitivity dependent on outside temperature and humidity? 


\section{Acknowledgements}

The work was partly funded by the Austrian Federal Ministry of Agriculture, Forestry, Environment and Water Management under contract No 14 4444/14-I/4/99.

\section{REFERENCES}

Defoer, N.; van Langenhove, H.; 2003. Determination of odour emissions from pig farms for regulatory purposes in Flanders. in International Symposium on Gaseous and Odour Emissions from Animal Production Facilities. 152-160, Horsens, Denmark.

Department of Sustainability and Environment, 2000. Victorian code for best practice broiler chicken farms. Interim Report. Victoria, Australia

Environment Agency, 2002. Integrated Pollution Prevention and Control (IPPC). Horizontal Guidance for Odour Part 1 - Regulation and Permitting (draft). Scientific and Technical Information Service, Bristol, UK.

Fang, L., Claosen, G., Fanger, P. O., 1998. Impact of temperature and humidity on the perception of indoor quality during immediate and longer whole-body exposure. Indoor Air, 8, 276-284

Iowa State University and The University of Iowa Study Group, 2002. Iowa concentrated animal feeding operations air quality study. Final Report. Iowa

Jacobson, L.D.; Guo, H.; Schmidt, D.R.; Nicolai, R.E.; 2001. Influence of weather conditions on field evaluatiuon of odour dispersions from animal production sites. $6^{\text {th }}$ International Livestock Environment Symposium, ASAE Pub No 701P0201.

Lohr, L.; 1996. Perception of rural air quality: What will the neighbors think? Journal of Agribusiness, 14, 109-128.

Miedema, H. M. E.; Walpot, J.I.; Vos, H.; Steunberg, C.F.; 2000. Exposure-annoyance relationship for odour from industrial sources. Atmos Environm 43, 2927-2936.

Miedema, H. M. E.; Ham, J. M.; 1988. Odour annoyance in residential areas. Atmospheric Environment, 22 (11), 2501-2507

Miner, J. R.; 1995. A review of literature on the nature and control of odors from pork production facilities. National Pork Producer Council, Des Moines, IA, USA.

Ministrie van Landbouw, 1991. Richtlijn Ammoniak en Veehouderij. Leidschendam: Ministrie van Landbouw, Naturbeheer en Visserij, Den Haag en Ministrie van Volkshuisvesting, Ruimtelijke Ordening en Milieubeheer.

Ministry for the Environment, 2003. Good Practice Guide for Assessing and Managing Odour in New Zealand. Air Quality Report, 36, Wellington (www.mfe.govt.nz)

Misselbrook, T.H.; Clarkson, Pain, C.R.; B.F.; 1993. Relationship between concentration and intensity of odour for pig slurry and broiler houses. $J$ of Agricultural Engineering Research, 55, 163-169

Nicell, J.A.; 1994. Development of the odour impact model as a regulatory strategy. Int. J. Environment and Pollution, 4, 124-138.

NSW Environment Protection Authority, 2001. Approved methods and guidance for the modelling and assessment of air pollutants in New South Wales. Sydney, Australia

ÖNorm M 9440, 1992/1996. Ausbreitung von luftverunreinigenden Stoffen in der Atmosphäre; Berechnung von Immissionskonzentrationen und Ermittlung von Schornsteinhöhen [Dispersion of pollutants in the atmosphere - calculation of the ambient air concentrations and determination of stack heights]. Österreichisches Normungsinstitut, Vienna.

Piringer, M.; Schauberger, G.; 1999. Comparison of a Gaussian Diffusion Model with Guidelines for Calculating the Separation Distance between Livestock Farming and Residential Areas to Avoid Odour Annoyance. Atmospheric Environment, 33, 2219-2228 
Reuter, H.; 1970. Die Ausbreitungsbedingungen von Luftverunreinigungen in Abhängigkeit von meteorologischen Parametern [Dispersion conditions of airborne pollutants in dependence on meteorological parameters]. Archiv für Meteorologie und Geophysik, Bioklimatologie A, 19, 173186

Richner, B.; Schmidlin, A.; 1995. Mindestabstände von Tierhaltungsanlagen. Empfehlungen für neue und bestehende Betriebe, Tänikon: Eidgenössische Forschungsanstalt für Betriebswirtschaft und Landtechnik, FAT-Bericht, 476.

Schauberger, G.; Piringer, M.; Petz, E.; 2002. Calculating direction-dependent separation distance by a dispersion model to avoid livestock odour annoyance. Biosystems Engineering, 82 (1) 1-24

Schauberger, G.; Piringer, M.; Petz, E.; 2001. Separation distance to avoid odour nuisance due to livestock calculated by the Austrian odour dispersion model (AODM). Agriculture, Ecosystems \& Environment, 87 (1) 13-28

Schauberger, G.; Piringer, M.; Eder, J.; Fiebiger, H.; Köck, M.; Lazar, R.; Pichler-Semmelrock, F.; Quendler, T.; Swoboda, M.; Thiemann, G.; Teufelhart, J.; 1997. Österreichische Richtlinie zur Beurteilung von Immissionen aus der Nutztierhaltung in Stallungen [Austrian guideline for the evaluation of ambient concentrations due to farming inside livestock buildings]. Gefahrstoffe - Reinhaltung der Luft, 57 (10) 399-408

Schauberger, G.; Piringer, M.; Petz, E.; 1999. Diurnal and annual variation of odour emission of animal houses: a model calculation for fattening pigs. Journal of Agricultural Engineering Research, 74 (3) 251-259

Schauberger, G.; Piringer, M.; Petz, E.; 2000a. Diurnal and annual variation of the sensation distance of odour emitted by livestock buildings calculated by the Austrian odour dispersion model (AODM) Atmospheric Environment, 34 (28) 4839-4851

Schauberger, G.; Piringer, M.; Petz, E.; 2000b. Steady-state balance model to calculate the indoor climate of livestock buildings demonstrated for fattening pigs. International Journal of Biometeorology, 43 (4) 154-162

Schauberger, G.; Piringer, M.; 1997a. Assessment of the protection distance to avoid annoyance by odour sensation caused by livestock husbandry by the Austrian guide line. In: Voermans J.A.M., G.J. Monteny (Eds): Ammonia and Odour Emission from Animal Production Facilities, NVTL, Rosmalen 1997

Schauberger, G.; Piringer, M.; 1997b. Guideline to assess the protection distance to avoid annoyance by odour sensation caused by livestock husbandry. In: Bottcher R.W., Hoff S.J. (Eds): Livestock Environment V, ASAE, St. Joseph, Michigan, 1997

Schiffman, S. S.; 1994. Psychological effects of swine odor on humans. International Round Table on Swine Odor Control. Proceedings p 8-11, Iowa State University

Strauss, G.; Cervinka, R.; Haider, M.; 1986. Erhebung über die Geruchsbelästigung in der Umgebung von Massentierhaltungen - eine Feldstudie [Survey of odour nuisance in the vicinity of livestock - a field study]. Inst of Environm Hygiene, Univ Vienna, Vienna.

Thu, K.M.; 2002. Public health concerns for neighbors of large-scale swine production operations. Journal of Agricultural Safety and Health, 8 (2)175-184.

van Langenhove, H.; van Broeck, G.; 2001. Applicability of sniffing team observations: experience of field measurements Water Science \& Technology, 44, 65-70

VDI, 3471, 1986. Emissionsminderung Tierhaltung - Hühner [Emission abatement of livestock - poultry], Berlin: Beuth.

VDI, 3472, 1986. Emissionsminderung Tierhaltung - Schwein [Emission abatement of livestock - pig], Berlin: Beuth.

Watts, P. J.; Sweeten, J. M.; 1995. Toward a better regulatory model for odour. Feedlot waste management conference. Chapter 15. Proceedings, Feedlot Waste Management Conference, Torrey Pines resort, Gold Coast, Queensland, Australia. 12-14 June. 10 p 